\title{
Editorial
}

\section{Revista Conversas e Controvérsias - v. 6, n.1, 2019}

\author{
Conversations and controversies (Journal) - v. 6, n.1, 2019
}

Teresa Cristina Schneider Marques

Editora

A revista Conversas e Controvérsias chega ao seu nono ano de existência com a publicação do presente número. Ele é marcado pelas mudanças no processo editorial incentivadas pela Editora da PUCRS (EDIPUCRS) e possibilitadas pela ampliação do apoio ofertado à equipe editorial da revista pela univerisidade por meio de um bolsa de apoio técnico (BPA), voltada para as ações que buscam alcançar um melhor padrão de qualidade da revista. Assim, a bolsa permitiu a integração de Ana Carolina Homem à equipe editorial, estudante da graduação em Ciências Sociais da PUCRS, que, após treinamento com o EDIPUCRS, passou a representar uma importante contribuição para a revista, além de permitir a ampliação da integração entre alunos da graduação e da pós-graduação na equipe.

Quanto às sessões, assim como os dois números anteriores, número 1 do ano de 2019 também apresenta um dossiê submetido à chamada pública que foi publicizada em 2017. Na edição número 01 de 2018, publicamos o dossiê temático temático intitulado "Dinâmicas contemporâneas das mobilizações sociais", organizado por pesquisadores vinculados à Universidade Federal do Rio Grande do Sul (UFRGS) e à Universidade Federal de Pelotas (UFPel) que discutiu as mobilizações sociais no atual contexto político (Espíndula ; Farias ; Rech ; Silva, 2018). Por sua vez, na edição número 02 de 2018, publicamos o dossiê "Partidos e representação política”, organizado por pesquisadores vinculados à Pontifícia Universidade Católica do Rio Grande do Sul (PUCRS), Universidade Federal do Paraná (UFPR) e à Universidade Federal de Pernanbuco (UFPE). O dossiê abordou a democracia representativa a partir de diferentes análises empíricas e teóricas sobre partidos no Brasil (Madeira; Quadros; Roeder ; Zucccolloto, 2018).

O presente número apresenta pela primeira vez um dossiê vinculado à pesquisadores da Universidade de São Paulo (USP) e voltado para a área de Relações Internacionais. O dossiê "Meio ambiente e Relações Internacionais" foi organizado por Cínthia Leone Silva dos Santos, doutoranda 
do Programa de Ciência Ambiental da USP, Isabela Battistello Espíndola, doutoranda do Programa de Geografia Humana da USP e Wagner Costa Ribeiro, pesquisador do CNPq, geógrafo e professor Titular da Faculdade de Filosofia, Letras e Ciências Humanas da USP. Na apresentação, os organizadores trazem um breve debate sobre a atualidade da questão ambiental para os estudos na área de relações internacionais. A atualidade do tema proposto pelo dossiê ficou comprovada pelo grande número de textos submetidos à avaliação cega efetivada pelos pareceristas anônimos que contribuem com a revista Conversas e Controvérsias. Entre os artigos submetidos e aprovados, cinco foram selecionados para compor o dossiê temático.

Além do dossiê temático, o presente número mantém ainda as sessões que foram adotadas a partir de 2016. Com efeito, em "Artigos livres", contamos com o artigo intitulado "Populismo e democracia em Francisco Weffort" de autoria de Marlon Antônio Ferreira. Por fim, em "Resenha", contamos com o texto de autoria de Maurício Michel Rebello e Matheus Gome Pereira intitulado "Instituições e prosperidade", uma resenha crítica da obra Why Nations Fail (2012) de Daron Acemoglu e James Robinson.

Diferentes instituições são representadas no presente número. São elas: Universidade Federal de Santa Catarina (UFSC), Universidade de Brasília (UNB), Universidade de São Paulo (USP), Universidade Federal de São João Del Rei (UFSJ), Universidade Federal do Estado do Rio de Janeiro (UNIRIO), Centro Universitário La Salle do Rio de Janeiro (UNILASALLE-RJ), Universidade Católica de Petrópolis (UCP), Universidade de Franca (UNIFRAN), Faculté de Droit et de Science Politique Aix-Marseille Université (França), Universidade Federal da Fronteira Sul (UFFS), Universidade Federal do Rio Grande do Sul (UFRGS) e Pontifícia Universidade Católica do Rio Grande do Sul (PUCRS). Os resultados de pesquisas apresentadas no presente número foram financiadas por diferentes agências de fomento, a saber: Comissão de Aperfeiçoamento de Pessoal de Ensino Superior (CAPES) e Conselho Nacional de desenvolvimento Científico e Tecnológico (CNPq).

Para finalizar, além de agradecer aos organizadores do dossiê temático e autores das diversas sessões, gostaria de fazer um agradecimento aos alunos do programa de pós-graduação e da graduação em Ciências Sociais da PUCRS que compõem a equipe editorial, em especial aos alunos que se dedicaram mais ao presente número: Felipe Rocha de Carvalho, Lara Augustina Sosa Marquez e Ana Carolina Homem. Agradeço ainda ao aluno da graduação Daniel Sobottka pelas contribuições ofertadas ao presente número da revista enquanto estágiário.

No mais, desejo à todos um bom proveito das contribuições apresentadas no número 01 de 2019 da Revista discente Conversas e Controvérsias!

\section{Referências}

Espíndula, B.; C. Farias, C.; Rech, C.; Silva, M. Apresentação: Dinâmicas contemporâneas das mobilizações sociais. Conversas e Controvérsias, Porto Alegre, v. 5, n. 1, p. 04-07, jan-jun., 2018. Disponível em: http://revistaseletronicas.pucrs.br/ojs/index.php/conversasecontroversias/article/ view/32069/17307. Acesso em: 30 jun. 2019. https://doi.org/10.15448/2178-5694.2018.1.32069

Madeira, R.; Quadros, M.; Roeder, K.; Zucccolloto, V. Apresentação: Partidos e representação política. Conversas e Controvérsias, Porto Alegre, v. 5, n. 2, p. 222-231, ago-dez, 2018. Disponível em : http:// 
revistaseletronicas.pucrs.br/ojs/index.php/conversasecontroversias/article/view/33079/17704. Acesso em: 30 jun. 2019. https://doi.org/10.15448/2178-5694.2018.2.33079

\section{Biografia do Autor}

\section{Teresa Cristina Schneider Marques}

Doutora (2011) em Ciência Política pela Universidade Federal do Rio Grande do Sul (UFRGS), com estágio doutoral no Institut d'Études Politiques de Paris (Sciences Po). Coordenadora do curso de graduação em Ciências Sociais da Pontifícia Universidade Católica do Rio Grande do Sul (PUCRS). Professora adjunta do Programa de Pós-graduação em Ciências Sociais da PUCRS. Editora da Revista Conversas e controvérsias. ORCID : http://orcid.org/0000-0002-6038-2704; E-MAIL : teresa.marques@pucrs.br.

Instituição: Pontifícia Universidade Católica do Rio Grande do Sul. Localização : Av. Ipiranga, 6681 -Partenon - Porto Alegre/RS 